\title{
Biotecnología para el desarrollo de naciones pequeñas
}

\author{
Jorge A. Huete-Pérez \\ Biólogo molecular, director del Centro de Biología Molecular de la UCA
}

El reciente apogeo que ha tenido la biología -muy por encima de las demás ciencias fundamentales- ha conllevado a que este centenario se venga considerando como el siglo de la biología. En particular, destacan los impresionantes descubrimientos de la biología molecular y sus innumerables aplicaciones en la medicina y la agricultura.

Desde la fundación del Centro de Biología Molecular de la Universidad Centroamericana (UCA), próximo a alcanzar su primera década de existencia, hemos venido insistiendo en impulsar el desarrollo de la biotecnología en Nicaragua. Puesto que en este ámbito el predominio de las naciones más ricas es casi absoluto, vale la pena preguntarse: ¿Qué oportunidades reales tiene un país en vías de desarrollo y más aún una nación tan pequeña como Nicaragua? ¿Cuáles son los obstáculos que se deben confrontar para posesionarse en el mercado global de la biotecnología? En esta reflexión tratamos de responder estas interrogantes, concluyendo que el actual esfuerzo de promoción de la biotecnología -visualizada como un nicho estratégico- debería ser parte integral de una estrategia general de desarrollo, enfocándose en resolver problemas trascendentales del país.

\section{El ámbito de la biotecnología}

Antes de explicar por qué se debería promover la biotecnología en los países pequeños y, además, dado que en la actualidad el término biotecnología viene siendo utilizado con demasiada libertad, conviene precisar sobre su ámbito y alcances.

La esfera de la investigación biotecnológica abarca una gama diversa de las ciencias. Se entiende por biotecnología la utilización de organismos vivos o derivados de éstos en la obtención de productos de valor para el ser humano. Esta definición comúnmente aceptada, permite una enorme flexibilidad en cuanto a las tecnologías y aplicaciones. Ateniéndonos a esta definición amplia, la biotecnología bien puede comprender la producción de insulina a partir de bacterias recombinantes, así como también la obtención de bioetanol y biodiesel a partir de caña de azúcar y soya, respectivamente. Bien encontramos aplicaciones médicas como la hormona del crecimiento, así como en la agricultura se cuenta con soya resistente a herbicidas y arroz con beta-caroteno.

Tradicionalmente se ha aplicado la biotecnología empleando microorganismos en la producción de vino, cerveza, queso y pan. Pero mencionemos que en tiempos más recientes el predominio y la punta de lanza son de la genómica y estudios sobre células troncales. Es este rango de la biotecnología denominada moderna, con procesos que 
emplean tecnologías inventadas más recientemente y sus aplicaciones industriales, el que llama la atención del público general. Nos referimos a temas de impacto como la clonación animal, el genoma humano y el uso de células troncales por mencionar aquellos de los que se habla con mayor frecuencia en los medios de comunicación.

Hoy día la "biotecnología moderna" emplea un conjunto de disciplinas y técnicas nuevas como clonación terapéutica, células troncales y terapia génica, que provienen de otras como la biología celular y molecular, la microbiología y la inmunología, a las cuales se agregan la biofísica y la bioinformática. Por otra parte, algunos círculos académicos conciben la biotecnología moderna más estrictamente como ingeniería genética (llamada también de ADN recombinante), una disciplina surgida hace unos 20 años que permite modificar y transferir genes de un organismo a otro, como por ejemplo en la creación de plantas transgénicas.

\section{Biotecnología como herramienta para mejorar la economía}

El mercado mundial de la biotecnología se estima alrededor de un billón de dólares mientras que en biotecnología agrícola, en particular, se calcula en 9,000 millones de dólares y se espera que para 2010 alcance los 25,000 millones. Solamente la compañía DuPont -una de las más grandes del mundo- invierte cerca de 500 millones de dólares anuales, mientras Syngenta -dedicada exclusivamente a la industria agrícola- invierte al menos 400 millones en investigación biotecnológica.

Conscientes de la importancia de la biotecnología para el crecimiento económico, no solamente los países desarrollados como Estados Unidos, Japón y muchos países europeos han decidido invertir en este sector, sino también países en vías de desarrollo como Argentina, Chile, México y Brasil. Brasil, que viene invirtiendo millones de dólares en los últimos años, implementa desde 2007 nuevas políticas, incentivos y programas con los que aspira a convertirse en uno de los primeros cinco polos mundiales, esperando inversiones anuales de cerca de 500-1,000 millones de dólares.

El caso de Cuba es muy singular porque a pesar de su crisis económica se calcula que ha destinado unos dos mil millones de dólares en biotecnología de la salud y hoy posee exportaciones de alrededor de 300 millones de dólares en medicamentos de origen biotecnológico. Del mismo modo se encuentran modelos exitosos de desarrollo biotecnológico en Egipto, la India y Corea del Sur.

En lugar de competir con las grandes naciones y empresas por la generación y comercialización de productos biotecnológicos tradicionales, los países pequeños pueden emplear la biotecnología como una herramienta para la generación de algunos productos nuevos tomando como insumos la vasta diversidad biológica común en el trópico. Este tipo de procesos de bioprospección comprende la explotación de la biodiversidad con el fin de otorgar valor comercial a los recursos genéticos y bioquímicos.

La bioprospección relacionada a la biodiversidad se entiende como la búsqueda sistemática de genes, componentes naturales y organismos completos en la naturaleza, buscando darles un potencial para el desarrollo de productos. Esta actividad relaciona exitosamente la base 
del conocimiento tradicional y medicina botánica con las herramientas biotecnológicas en la generación de nuevos productos. Se ha estimado que en la actualidad, cerca de la mitad de los productos farmacéuticos son derivados de plantas y que en los países pobres, más del $80 \%$ de la población utiliza algún tipo de medicina botánica.

En cuanto a bioprospección en Centroamérica, el ejemplo del que más se habla es la experiencia del INBio, Instituto Nacional de Biodiversidad, de Costa Rica, que además de ingresos, ha dejado una enorme experiencia de investigación y conocimiento sobre la biodiversidad del país. Los procesos de bioprospección presentan algún grado de complejidad para países pequeños, por lo que muchos países procuran alianzas para la formación de capacidades sobre el tema.

Según un estudio de la Comisión Económica Para América Latina y el Caribe (CEPAL), los países andinos (Colombia, Perú, Venezuela, Bolivia y Ecuador) contienen una gran riqueza de diversidad biológica y la biotecnología moderna ofrece la oportunidad de convertirla en elemento de desarrollo económico y social a través de su valoración, uso sostenible y conservación. El uso del camote para combatir la carencia de vitamina A en África y el hallazgo en Colombia de un biofungicida contra plagas del frijol son dos muestras convincentes del potencial de la biodiversidad andina que puede ser aprovechado por medio de la biotecnología para beneficio económico y social.

\section{Biotecnología para la seguridad alimentaria}

La biotecnología podría servir también como herramienta para apoyar la seguridad alimentaria de los países pequeños. Por un lado, se puede procurar el rescate y desarrollo de los cultivos de subsistencia que culturalmente son de mucha importancia para las naciones pequeñas, así como para grupos étnicos minoritarios. Existen algunas experiencias importantes sobre la identificación de especies y variedades de importancia agronómica local.

Por otra parte, la biotecnología tiene mucha aplicabilidad en diversos aspectos de la seguridad alimentaria como el cumplimiento de normas de bienestar animal y de calidad e inocuidad de los alimentos, prevención de enfermedades relacionadas con los alimentos, y programas de los sistemas de control para que operadores económicos y consumidores encuentren un referente de garantía para aumentar la confianza de los consumidores. Otro aspecto es el uso de herramientas moleculares en la vigilancia epidemiológica, importante para la seguridad alimentaria.

La biotecnología ofrece enormes posibilidades para mejorar los sistemas de seguridad alimentaria, tanto de forma directa como indirecta. La biotecnología se emplea cada vez más en los sistemas de trazabilidad. Los nuevos métodos biotecnológicos de detección de agentes patógenos presentan mejor sensibilidad y mayor versatilidad en sus posibilidades de aplicación, mejorando los sistemas de control. También hay técnicas moleculares útiles en la mejora de los procesos productivos y la conservación de alimentos, incidiendo en la mejora de la seguridad alimentaria. 


\section{Oportunidades}

A pesar de diversas dificultades -como la falta de una masa crítica mínima, carencia de inversión y poco involucramiento del sector productivo local- aun países pequeños como Nicaragua presentan formidables oportunidades para el desarrollo endógeno de la biotecnología. No debería pasar desapercibido el hecho de que las tres cuartas partes del total de publicaciones de investigadores nicaragüenses registradas en bases de datos internacionales están dedicadas a salud y medioambiente (disciplinas de las ciencias naturales). De modo que las capacidades existentes en investigación biomédica, como microbiología, bioquímica, biodiversidad, epidemiología y más recientemente en biología molecular, junto al boom experimentado en las tecnologías de la información, representan una oportunidad, una base sólida sobre la cual se pueden organizar programas integrales de investigación y desarrollo biotecnológico.

Además, la enorme diversidad natural con que cuenta Nicaragua podría representar una excepcional oportunidad para el descubrimiento de proteínas y genes de interés industrial para la medicina y la agricultura. La Universidad Centroamericana, además de contar con el Centro de Biología Molecular (CBM-UCA) y su programa de análisis genético, cuenta con una vasta experiencia en acuicultura, medioambiente y biodiversidad. Todos estos elementos son factores fundamentales que podrían tomarse en cuenta para la formulación de programas interdisciplinarios de investigación.

Por otra parte, el rescate del conocimiento tradicional de la flora nacional, potenciado a través de la industrialización biotecnológica, es otra oportunidad de incalculable valor. Un esfuerzo encaminado en esta dirección con interés en bioprospección son los nexos entre el CBM-UCA y la compañía New England Biolabs, Inc., así como también con la compañía Bioscientífica recientemente establecida en Nicaragua y Estados Unidos.

De la experiencia exitosa de varios países en vías en desarrollo, como los mencionados anteriormente, se pueden rescatar varias lecciones para las naciones pequeñas ${ }^{1}$. Resulta indispensable contar con la voluntad política de los gobiernos para mantener el financiamiento sostenido y aplicado a las prioridades definidas por los Estados.

Otros factores de éxito incluyen el aseguramiento de que el desarrollo biotecnológico vaya a la par de las regulaciones y no desfasado, aprovechar las relaciones y redes internacionales existentes, definición de las áreas de fortaleza y prioridad, y la promoción de vínculos intersectoriales e interdisciplinarios.

El estado de la biotecnología en los países en vías de desarrollo difiere mucho de país a país. Exceptuando a Costa Rica, la situación en Centroamérica es bastante deficiente. Varios países latinoamericanos como Chile, Cuba, Panamá, Costa Rica y Perú, cuentan ya con ambiciosos programas de biotecnología enfocados a problemas concretos de sus pueblos. En estos casos incluso se emplea la ingeniería genética en la caracterización de germoplasmas y en el desarrollo racional de la mejora de los cultivos. En la búsqueda de transferencia

1 Health Biotechnology Innovations in Developing Countries. Nature Biotechnology. Supplement to Nature Publishing Group, December 2004 . 
de tecnología de punta y nuevos mercados, los centros e institutos de avanzada de estos países pequeños han establecido programas de cooperación con universidades y empresas del Primer Mundo.

También en Nicaragua se han dado algunas experiencias exitosas de investigaciones y proyectos que emplean algún tipo de técnica de biotecnología. Resaltemos algunos proyectos de investigación en salud pública sobre virología y parasitología (UNAN-León y UCA), uso de marcadores moleculares de interés entomológico y para caracterización de germoplasma (UNAN-León y UNA), caracterización de marcadores genéticos de la población nicaragüense (CBM-UCA), y una serie de servicios moleculares de utilidad para la acuicultura y la groindustria (CIDEA y CBM-UCA). La experiencia común de estos ejemplos, digna de reproducir, es haber contado con financiamiento continuo (público o privado) y un plan de investigación con pertinencia social, en función de resolver algunos problemas locales.

\section{Limitaciones que tienen que superarse en Nicaragua}

Si nos atuviésemos a la definición estricta de que biotecnología equivale a ingeniería genética, tendríamos que admitir que en Nicaragua no existe ninguna posibilidad de investigación ni aplicación biotecnológica modernas. Por una parte porque este tipo de investigación requiere de una inversión sostenida en ciencia básica de al menos 10-15 millones de dólares. La liberación de plantas transgénicas en los campos agrícolas, por ejemplo, requiere además de capacidad científica, de una infraestructura de evaluación y monitoreo, y de legislación específica al respecto que en el país es aún inexistente.

Por otra parte, y esta es una limitación medular, para su ejecución este tipo de investigación requiere ineludiblemente de una masa crítica de biólogos moleculares y agrónomosbiotecnólogos con nivel de doctor (Ph.D.) y, preferiblemente, con años de experiencia postdoctoral en países en los que se genera esta tecnología. Hasta ahora en nuestro país hay pocos doctores investigadores y la masa crítica es sumamente frágil aun en las universidades más importantes. La actual capacidad científica para abordar procesos biotecnológicos de envergadura está representada a lo sumo en 2 ó 3 grupos de investigación, lo cual indica que existe una capacidad incipiente que debería ser fortalecida. Además, si consideramos que la fortaleza de las naciones en el sector biotecnológico se estima según el monto de la inversión y el número de compañías biotecnológicas, el país no tendría razones para el optimismo.

Tomando en cuenta el interés que se ha generado en el país alrededor de la biotecnología y los esfuerzos y experiencia de algunos grupos universitarios de investigación que emplean algún tipo de técnica de la biotecnología amplia, no sería insensato ni prematuro plantear que nuestro país podría gradualmente avanzar hacia niveles superiores de desarrollo biotecnológico.

\section{Perspectivas para el desarrollo de la biotecnología en Nicaragua}

Para poder transitar de un estado de desarrollo biotecnológico incipiente a uno superior Nicaragua debe contar con apoyo decidido del Estado, lo que debería reflejarse en 
financiamiento de proyectos concursables y formulación de políticas y planes concretos de desarrollo biotecnológico.

El involucramiento del Estado debería procurar la pertinencia social de los proyectos, lo que implica que éstos deberían estar en función del desarrollo económico y social del país. Para ello resulta necesario garantizar los vínculos de los proyectos con los negocios respectivos y las cadenas productivas de mercados convenientes.

Desde hace algún tiempo venimos insistiendo en la necesidad de un programa nacional de biotecnología enfocado en el sector salud, agrícola y medioambiental. El Segundo Congreso Nicaragüense de Biotecnología (abril 2004), organizado por la UCA, recogió estas inquietudes en un pronunciamiento dirigido al gobierno y la ciudadanía en general. Este plan debería incluir la formación científica de recursos humanos adaptada a las necesidades reales del país, una selección depurada de proyectos de investigación identificados a partir de su relevancia económica y ambiental, la promoción de la transferencia de nuevas tecnologías y el establecimiento de nexos internacionales.

La reciente iniciativa para el desarrollo sectorial de la agrobiotecnología, implementada por el Instituto de Tecnología Agropecuaria, INTA, con la cooperación del gobierno de Finlandia y la Universidad de Helsinki, promete ser un esfuerzo en la dirección correcta. Cuidando atender las necesidades reales del agro nicaragüense, esta iniciativa podría servir de motivación para programas similares en el sector ambiental, industrial y de salud pública.

Un factor importante para el desarrollo biotecnológico es promover la vinculación del sector académico con el industrial, y el de emprendedurismo y negocios. Sin acceso adecuado a capital y sin capacidad de comercializar las innovaciones obtenidas, el esfuerzo resultaría frustrado por su falta de rentabilidad. La investigación biotecnológica -y la investigación, en general- debería desprenderse de su fachada puramente academicista y aparejarse más con el nivel empresarial.

Tiene que fomentarse mejor la comunicación entre las empresas y los centros universitarios de investigación. Deberían procurarse mecanismos mediante los cuales los resultados de las investigaciones pudiesen transferirse de manera tangible y mensurable a los sectores apropiados. Para garantizarlo lo ideal sería tratar de involucrar a todos los sectores interesados en un tema determinado de investigación desde la formulación misma de los proyectos. La pertinencia social de los proyectos debería ser uno de los criterios de selección de todas las propuestas.

\section{Reflexiones finales}

Puesto que Nicaragua dista mucho de competir en el mundo de las biotecnologías de vanguardia -y más aún si nos apegamos a la definición estricta de biotecnología moderna como ingeniería genética- sería mejor que nuestro país tratase de incorporar y adaptar los inventos tecnológicos más adecuados a nuestra realidad. Pero no se trata de convertirnos en simples usuarios, sino de usar la tecnología y apropiarla a nuestras necesidades e intereses económicos. En el caso específico de la agrobiotecnología, aun con la pequeña 
infraestructura de investigación existente, el país podría beneficiarse de avances como las nuevas semillas y material de propagación en la medida en que se tenga capacidad de usar y diseminar productos como plantas libres de patógenos y resistentes a enfermedades.

Sin descartar que puedan existir ya algunas plantas transgénicas de utilidad para las condiciones agronómicas de Nicaragua, antes que nuestros investigadores procuren la creación de variedades transgénicas, el país debería mejor invertir sus escasos recursos en aplicar la biotecnología a la identificación de cultivares naturalmente más resistentes y de mejor calidad nutricional. La biotecnología agrícola debería enfocarse en procurar primero que nada la seguridad alimentaria nacional y seguidamente la competitividad económica.

El creciente interés público por la biotecnología en Nicaragua no tiene mucho que ver con la importancia económica de la biotecnología dada la competencia de diversos países por el liderazgo de esta industria. La atención más bien se ha centrado sobre los aspectos éticos y de percepción pública relacionados al uso de estas tecnologías.

Desde posiciones ambientalistas y del derecho del consumidor, algunas organizaciones atacan a la biotecnología, principalmente de transgénicos. Pero hoy en día las normas de bioseguridad en el laboratorio y en los ensayos clínicos o de campo velan por que aquellos productos obtenidos a través de la biotecnología cumplan con las normas establecidas y que una vez comercializados no vayan a afectar ni la salud humana ni el ambiente. Para responder a estas preocupaciones ambientales, Nicaragua tiene que trabajar más en el fortalecimiento de la comisión nacional encargada de la evaluación de riesgos creada hace ya varios años por decreto presidencial.

Sin embargo, a nivel internacional, el consenso científico actual -refrendado en estudios de muchas academias de ciencias del mundo- es que los productos comercialmente disponibles son inocuos a la salud humana y el medio ambiente. En el caso de las plantas transgénicas se trata de tener la seguridad absoluta de que una vez liberadas al ambiente, éstas no vayan a convertirse en especies dominantes ni desplazar a otras.

Los aspectos bioéticos, por otra parte, deberían ser abordados de manera integral, serena y participativa. La creación de una comisión de bioética de carácter consultivo y propositivo daría confianza a la población y permitiría avanzar con decisiones apropiadas. La comisión, de carácter pluridisciplinario, integrada por especialistas de diversos temas, así como por ciudadanos no especialistas pero con compromiso social, tendría la tarea de discutir los temas más acuciantes y plantear salidas a los desafíos del momento y los que se avisten en el futuro próximo.

En todo esto, la participación pública no sería únicamente deseable sino una obligación democrática, lo cual nos obliga a garantizar la comprensión de estos temas por medio de programas de divulgación científica y, mejor aún, con la creación de una cultura científica. Si falláramos en implementar una cultura científica mínima que permita la comprensión de los retos y que facilite la participación ciudadana en la discusión y toma de decisiones sobre estos temas urgentes, continuaríamos siendo presas de quienes se benefician de la ignorancia y la superstición. 